Molecules 2005, 10, 978-989

molecules

ISSN 1420-3049

http://www.mdpi.org

\title{
Synthesis and Characterization of Nitro-p-xylenes
}

\author{
Liu Yan-Hong ${ }^{1}$, Zhang Tong-Lai ${ }^{1, *}$, Zhang Jian-Guo ${ }^{1}$, Guo Jin-Yu ${ }^{1}$ and Yu Kai-Bei ${ }^{2}$ \\ ${ }^{1}$ State Key Laboratory of Prevention and Control of Explosion, Beijing Institute of Technology, \\ Beijing 100081, P. R. China, Tel: +86-10-68911202, Fax: +86-10-68911202 \\ ${ }^{2}$ Center of Analysis and Test of Chengdu Branch, Chinese Academy of Sciences, Chengdu 610041, \\ P.R. China
}

* Author to whom correspondence should be addressed; E-mail: ztlbit@bit.edu.cn

Received: 25 January 2005; in revised form: 23 April 2005 / Accepted: 25 April 2005 / Published: 31 August 2005

\begin{abstract}
In this paper we elected to nitrate p-xylene because this compound has only one mononitro- and trinitro- isomer. Trinitro-p-xylene was used as a starting material for the synthesis of other compounds in subsequent work. The mononitration of p-xylene can be easily carried out at $30^{\circ} \mathrm{C}$. Nitro-p-xylene is easily nitrated to dinitro-p-xylene at a temperature of $80^{\circ} \mathrm{C}$. The trinitro-p-xylene can be obtained at $120^{\circ} \mathrm{C}$. Single crystals of 2,3-dinitro-p-xylene and 2,3,5-trinitro-p-xylene were grown using the slow cooling method and we report the X-ray structure of the former. The thermal decomposition of the compounds was studied using differential scanning calorimetry (DSC) and thermogravimetry-derivative thermogravimetry (TG-DTG) techniques and FT-IR. The target compounds were also characterized by ${ }^{1} \mathrm{H}-\mathrm{NMR},{ }^{13} \mathrm{C}-\mathrm{NMR}$ and MS.
\end{abstract}

Keywords: p-Xylene, Nitration, Thermal Analysis

\section{Introduction}

The nitration of $p$-xylene to give the corresponding mononitro- $p$-xylene, dinitro- $p$-xylene (DPX) and trinitro- $p$-xylene (TPX) has been studied many years ago. Prior to World War II the nitration of the xylenes was carried out only on a small scale to produce solvents and chemical intermediates. However, during the war mixed xylenes were nitrated in at least three government ordnance works and reduced to xylidines that were used as an additive to increase the octane rating of 
aviation grade gasoline. Numerous uses were suggested for the surplus xylidines at the end of the war, such as for dyes and intermediates, wood preservatives, wetting agents, accelerators for rubber, and frothing agents for the flotation of ores [1]. The production of xylenes by the hydroforming process used for the manufacture of toluene from petroleum hydrocarbons makes available large amounts of these three isomeric hydrocarbons. Their nitration represents the application of one of the important unit processes to give an intermediate compound for further chemical utilization [2].

p-Xylene was first nitrated by Glinzer and Fitting [3]. In 1885 Nolting and Forel [4] were the first to use the mixed sulfuric and nitric acids to nitrate $p$-xylene. Konowalow and Gurewitsch [5] nitrated a number of alkyl benzenes, including $p$-xylene, with mixed nitric and acetic acids. Two patents also describe the nitration of mixed xylenes. Batchelder [6] claimed a mononitro product low in dinitro and by-product impurities. Most of the previous work, which reported on the dinitro- compounds, has been incidental to the nitration of $p$-xylene. Glinzer and Fittig heated mononitro- $p$-xylene and fuming nitric acid to produce a solid mixture of dinitro compounds. Lellmann's [7] nitration method was to mix 25 grams of p-xylene and 100 grams of nitric acid (density, $1.51 \mathrm{~g} / \mathrm{cm}^{3}$ ) and allow them to stand for several days, however the yield was poor (only 2 grams of the 2,5-dinitro-p-xylene isolated from 100 grams of solid product). Giua [8] nitrated p-xylene with mixed acid and obtained only the 2,3-and 2,6-isomers.

Dinitro aromatic hydrocarbons may be made in either one or two steps [9-10], but it is more common to carry out the nitration in separate steps to reduce oxidation and also reduce the solubility of the product in the strong acid required for the one step process. For the nitration of nitro-p-xylene, it would be expected that the mixed acid would be less concentrated than for the dinitration of toluene but more concentrated than for the mononitration of $p$-xylene. Likewise, the temperature of nitration should be lower than for dinitration of toluene but higher than that used for the mononitration of $p$-xylene.

In this work, the para isomer is selected for its regular structure - only one mononitro and trinitro compounds exist - making it easier to obtain the single nitration compounds. Furthermore, the trinitro-p-xylene is the raw material of our subsequent work for its high nitrogen content. Trinitro-p-xylene has similar structure to 2,4,6-trinitrotoluene (TNT) which has been used traditionally as not only as a melt-case explosive but also a starting material for synthesis of two commonly used thermally stable explosives, i.e. 2,2',4,4',6,6'-hexanitrostilbene (HNS) [11] and 1,3,5-triamino2,4,6-trinitrobenzene (TATB) [12]. These compounds are high melting explosives that have been applied in situations where a combination of insensitivity to impact as well as heat is important.

In this paper, we have obtained mononitro- $p$-xylene, pure 2,6-dinitro- $p$-xylene, 2,3-dinitro$p$-xylene and trinitro- $p$-xylene. Furthermore, we have determined the molecular and crystal structures of 2,3-dinitro- $p$-xylene. The thermal properties of 2,3- and 2,6-DPX and TPX were studied in detail.

\section{Results and Discussion}

The single crystal structure [13]

The structure of the 2,3-DPX was determined by single crystal X-ray diffraction. Dimensions of the single crystal used for measurement were $0.40 \mathrm{~mm} \times 0.40 \mathrm{~mm} \times 0.30 \mathrm{~mm}$. Cell parameters were determined in the range of $2.64^{\circ}<\theta<27.48^{\circ}$ at the temperature of 293(2) K. 2094 independent 
reflections were obtained, among which 1096 observed reflections with $\mathrm{I}>2 \sigma(\mathrm{I})$ were used for the determination and refinement of the crystal structure in the range of $-9 \leq h \leq 9,-15 \leq k \leq 15,-13 \leq 1 \leq 13$. The crystal structure of 2,3-DPX is monoclinic with space group of P2(1)/n. The cell parameters are: a $=0.7594(2) \mathrm{nm}, \mathrm{b}=1.1825(2) \mathrm{nm}, \mathrm{c}=1.0331(2) \mathrm{nm} ; \beta=98.74(3)^{\circ}, \mathrm{V}=0.9170(3) \mathrm{nm}^{3}, \mathrm{Dc}=1.421 \mathrm{~g}^{\circ} \mathrm{cm}^{-3}$, $\mathrm{Z}=4, \mathrm{~F}(000)=408, \mu=0.116 \mathrm{~mm}^{-1}, \mathrm{Mr}=196.16$. The final $\mathrm{R}_{1}=0.0556$ (for observed data) and $\mathrm{wR}_{2}$ is 0.1520 (for data $\mathrm{I}>2 \sigma(\mathrm{I})$ ), $\mathrm{R} 1=0.0831$, wR2 $=0.1686$ (for all data). All calculations were carried out with SHELXS98 [14]. The unit structure and the packing of the molecule in crystal lattice are illustrated in Figures 1 and 2.

Figure 1. Molecular structure of DPX and the atom numbering

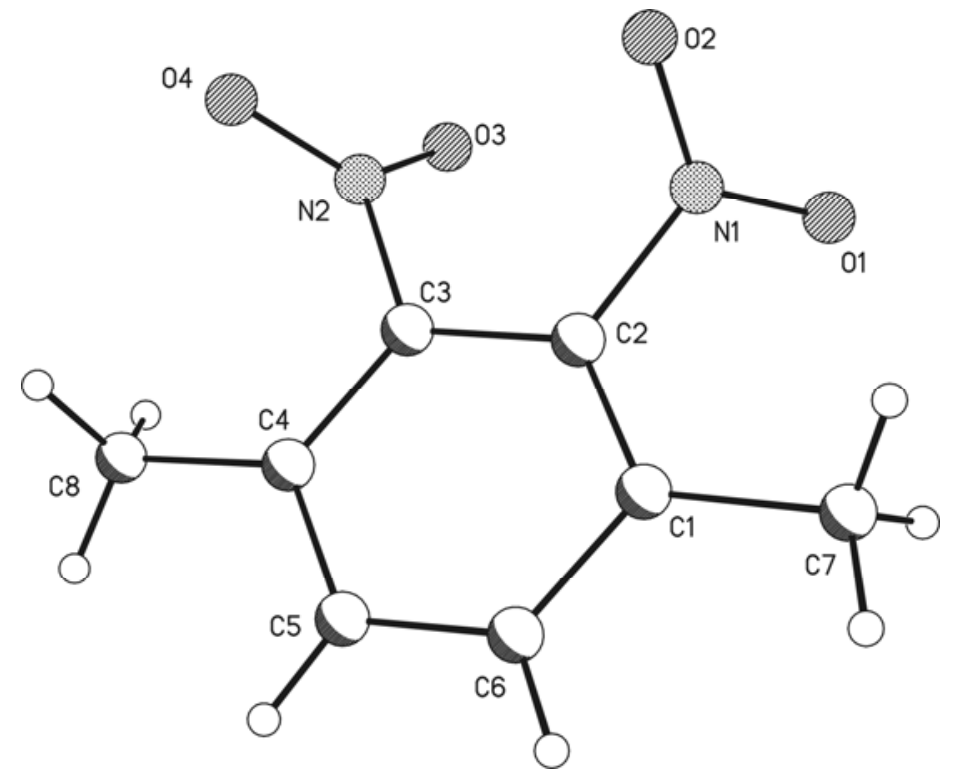

Figure 2. Crystal packing of DPX

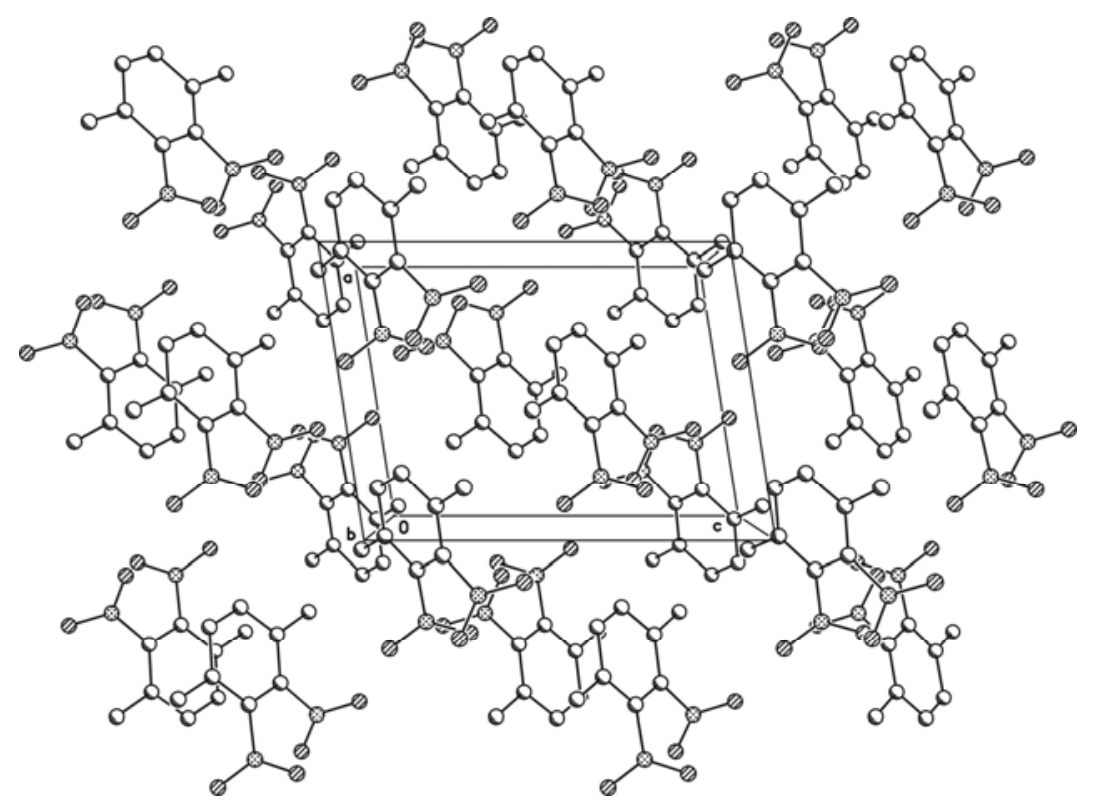


From Figures 1 and 2 we can see that the nitro groups are not coplanar. The torsion angles are similar: $\mathrm{O}(1)-\mathrm{N}(1)-\mathrm{C}(2)-\mathrm{C}(1)$ is $56.4^{\circ}, \mathrm{O}(2)-\mathrm{N}(1)-\mathrm{C}(2)-\mathrm{C}(1)$ is $-122.8^{\circ}, \mathrm{O}(4)-\mathrm{N}(2)-\mathrm{C}(3)-\mathrm{C}(4)$ is $57.8^{\circ}$, $\mathrm{O}(3)-\mathrm{N}(2)-\mathrm{C}(3)-\mathrm{C}(4)$ is $-122.4^{\circ}$ while $\mathrm{C}(1)-\mathrm{C}(2)-\mathrm{C}(3)-\mathrm{C}(4)$ is $-2.3^{\circ}$ and $\mathrm{O}(1)-\mathrm{N}(1)-\mathrm{C}(2)-\mathrm{C}(3)$ is $-125.0^{\circ}$, $\mathrm{O}(2)-\mathrm{N}(1)-\mathrm{C}(2)-\mathrm{C}(3)$ is $55.8^{\circ}, \quad \mathrm{O}(4)-\mathrm{N}(2)-\mathrm{C}(3)-\mathrm{C}(2)$ is $-124.9^{\circ}, \quad \mathrm{O}(3)-\mathrm{N}(2)-\mathrm{C}(3)-\mathrm{C}(2)$ is $54.9^{\circ}$. According to these data we present the "ball and stick" face and side face views of 2,3-DPX in Figure 3. The bond lengths of the crystal that are C-N 1.478, C1-C7 1.512, C4-C8 1.506 and the benzene $\mathrm{C}-\mathrm{C}$ length is between 1.378 and 1.396, within the normal bond length range.

Figure 3. The face and side face views of 2,3-DPX
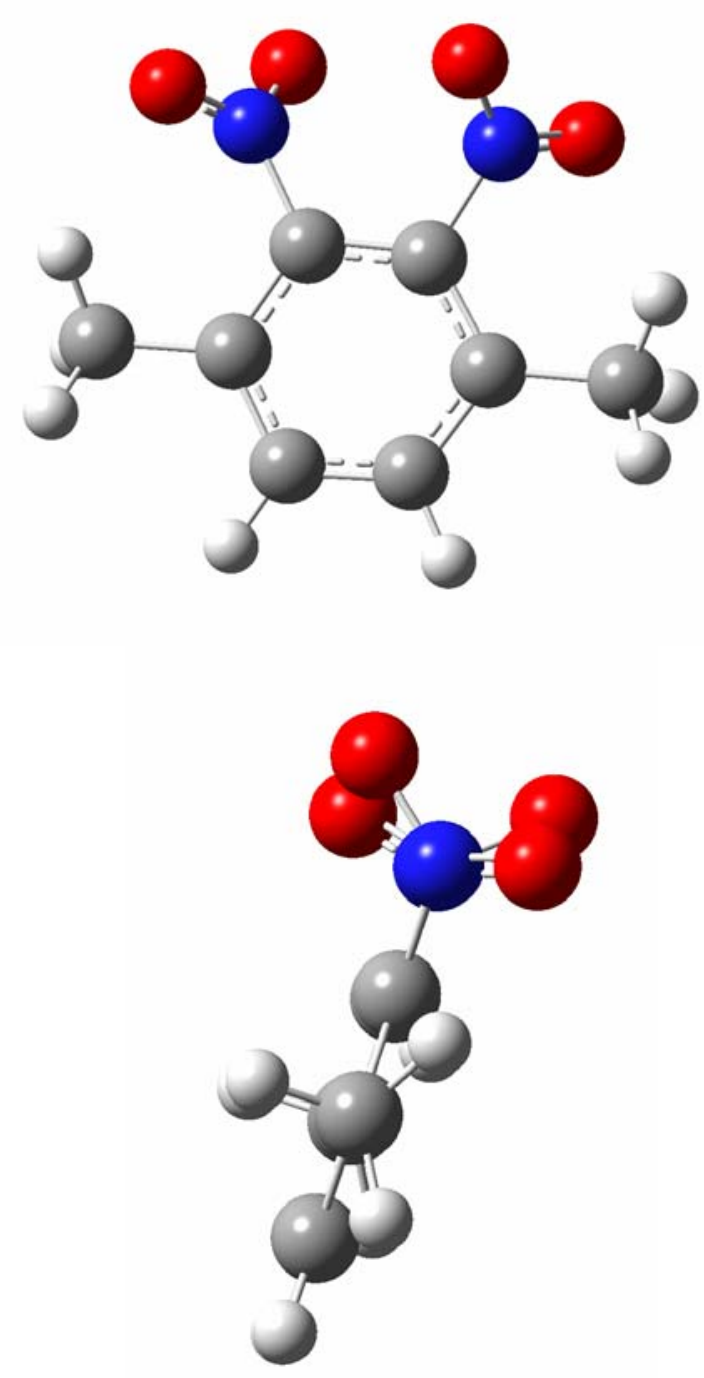

The single crystal structure of TPX (CCDC number 256461) is discussed in another paper, currently in press [15]

\section{Thermal behavior of the compounds}

Typical DSC and TG-DTG curves for the compound 2,6-DPX are shown in Figures 4 and 5. The DSC curve shows two endothermic peaks between $50{ }^{\circ} \mathrm{C}$ and $225^{\circ} \mathrm{C}$, with peak temperatures at 
$123.9^{\circ} \mathrm{C}$ and $202.9^{\circ} \mathrm{C}$, respectively. The first peak temperature corresponds to the melting point of 2,6-dinitro-p-xylene $\left(123^{\circ} \mathrm{C}\right.$ or $\left.126^{\circ} \mathrm{C}\right)$. The TG curve shows one stage mass loss without any stable intermediate products being formed in which the stage began at about $105.9^{\circ} \mathrm{C}$ and was completed at $192{ }^{\circ} \mathrm{C}$ accompanied by a $96.6 \%$ mass loss.

Figure 4. DSC curve of the 2,6-DPX

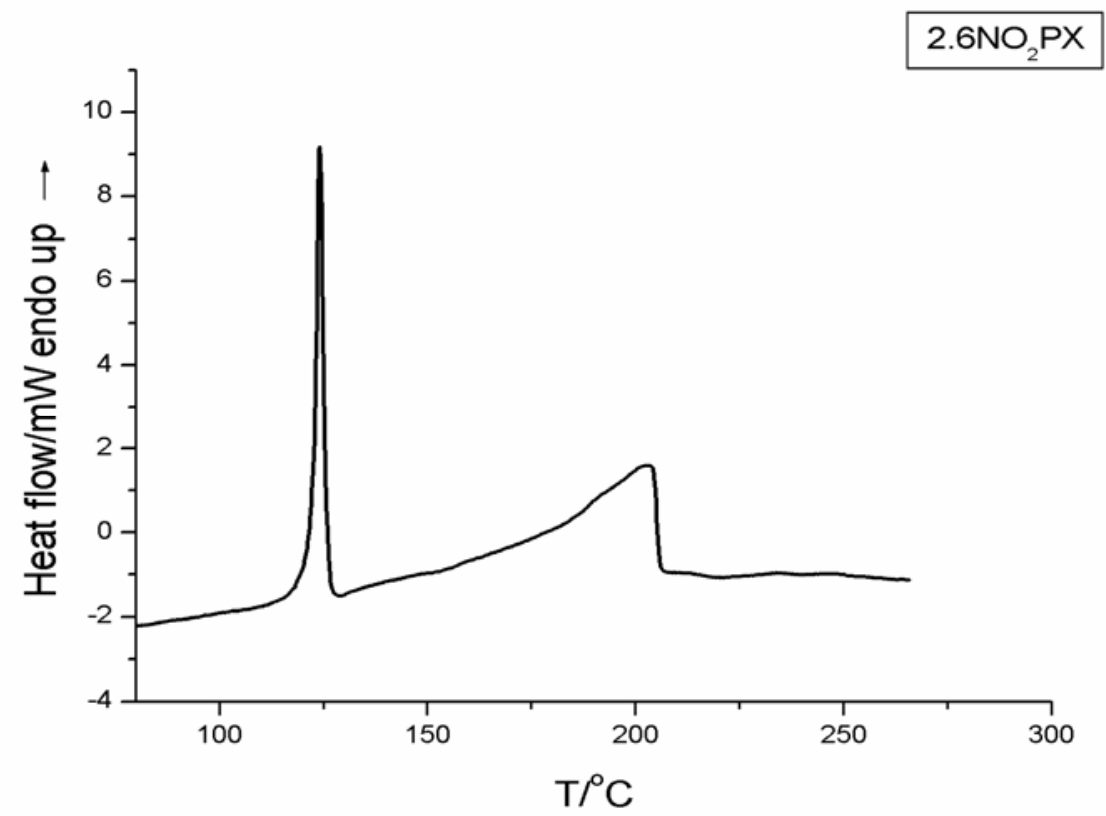

Figure 5. TG-DTG curve of 2,6-DPX

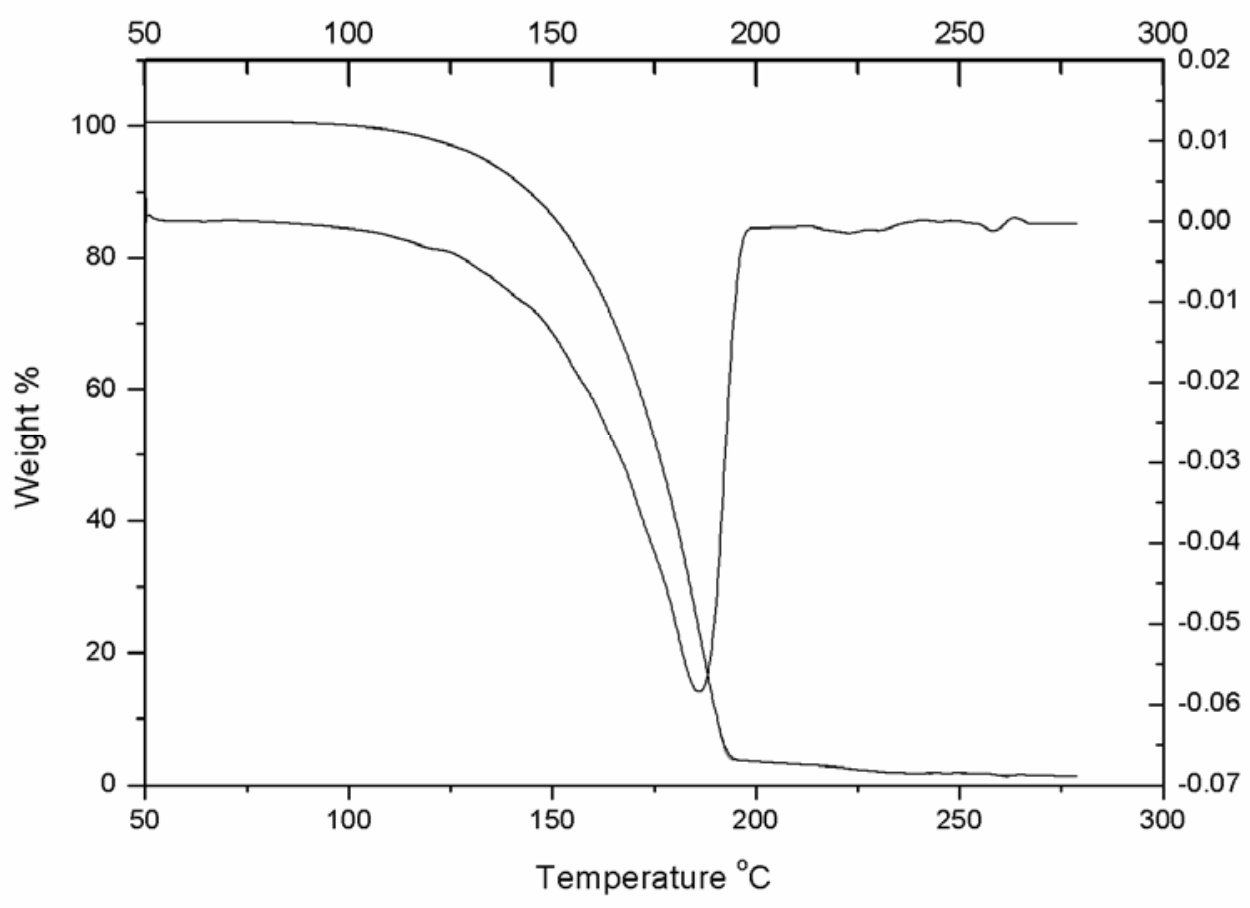


Figures 6 and 7 are the DSC and TG-DTG curves of 2,3-DPX. The curves are similar to those of 2,6-DPX as we can observe two endothermic peaks in Figure 6 and one stage mass loss in Figure 7. In the DSC curve the first endothermic peak temperature is at $92.8{ }^{\circ} \mathrm{C}$, which matches with the literature melting point of $90-93^{\circ} \mathrm{C}$.

Figure 6. DSC curve of 2,3-DPX

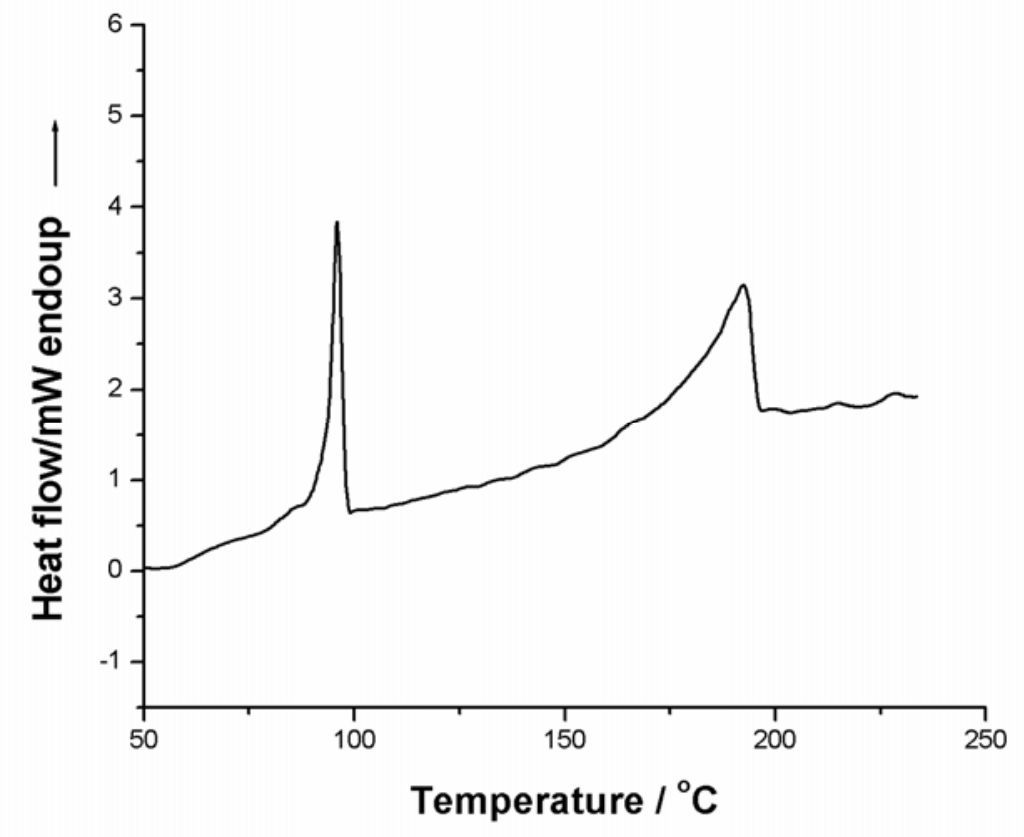

Figure 7. TG-DTG curve of 2,3-DPX

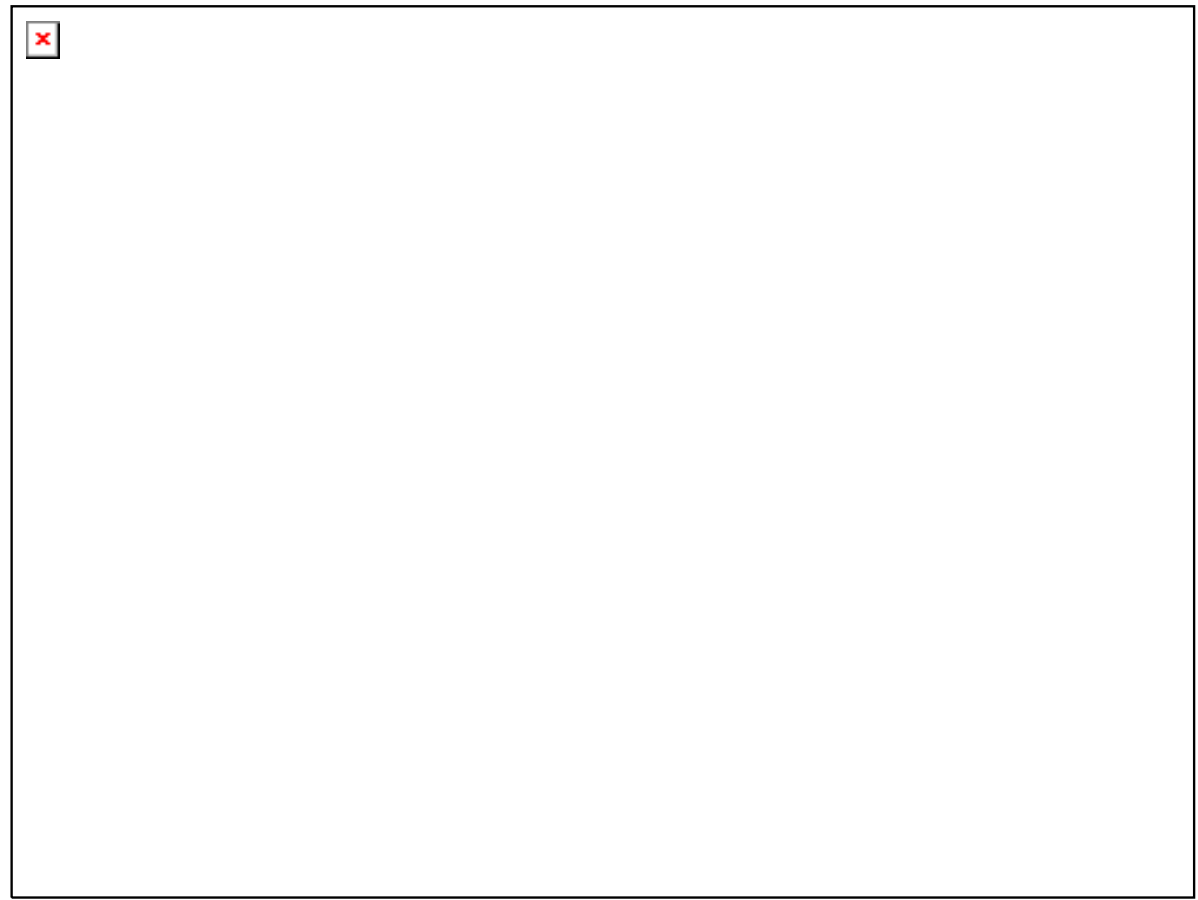

Figure 8 and Figure 9 are the DSC and TG-DTG curves of TPX. We can see that two endothermic peaks can be recognized in Figure 8 between room temperature and $245.0{ }^{\circ} \mathrm{C}$. The first intense endothermic peak has a peak temperature of $140.9{ }^{\circ} \mathrm{C}$, the same as the melting point of TPX 
$\left(139-140^{\circ} \mathrm{C}\right)$. To find out what the decomposition residues are, FT-IR analysis was performed. The IR spectra of the solid residues of TPX at room temperature and $150{ }^{\circ} \mathrm{C}$ are shown in Figure 10 . We can observe that the two curves have no difference according with the DSC and TG results. This also proved that the first peak of the DSC curve is the melting endothermic peak.

Figure 8. DSC curve of the TPX

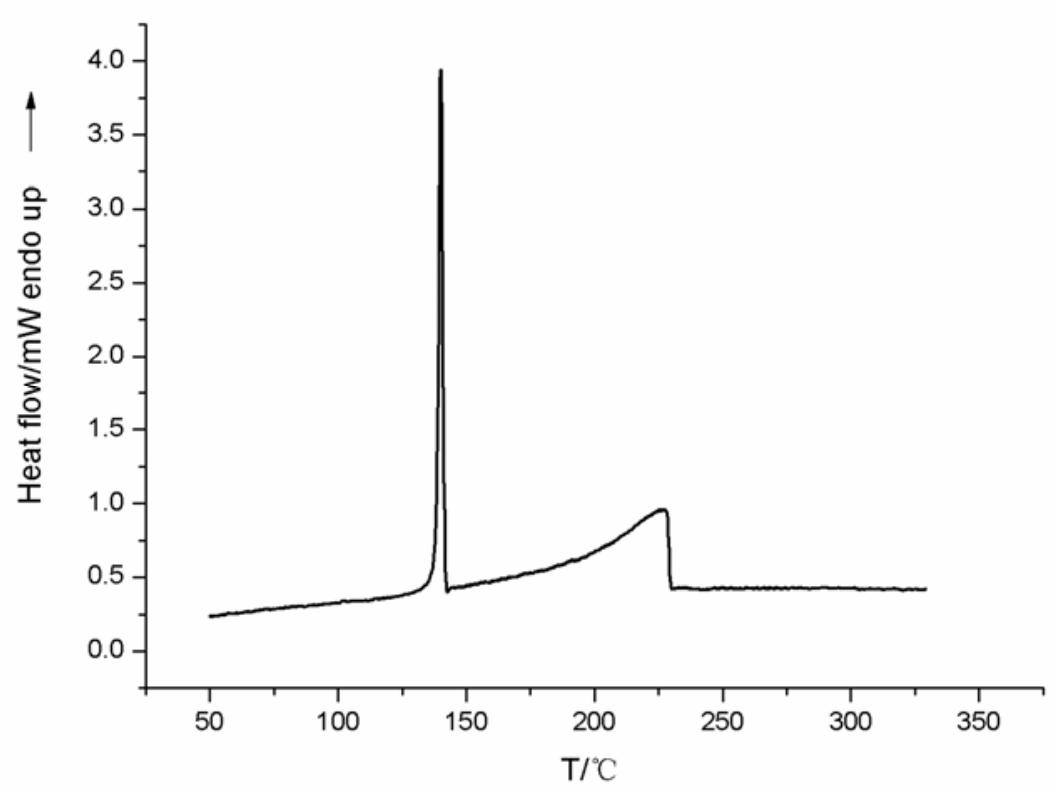

Figure 9. TG-DTG curve of TPX

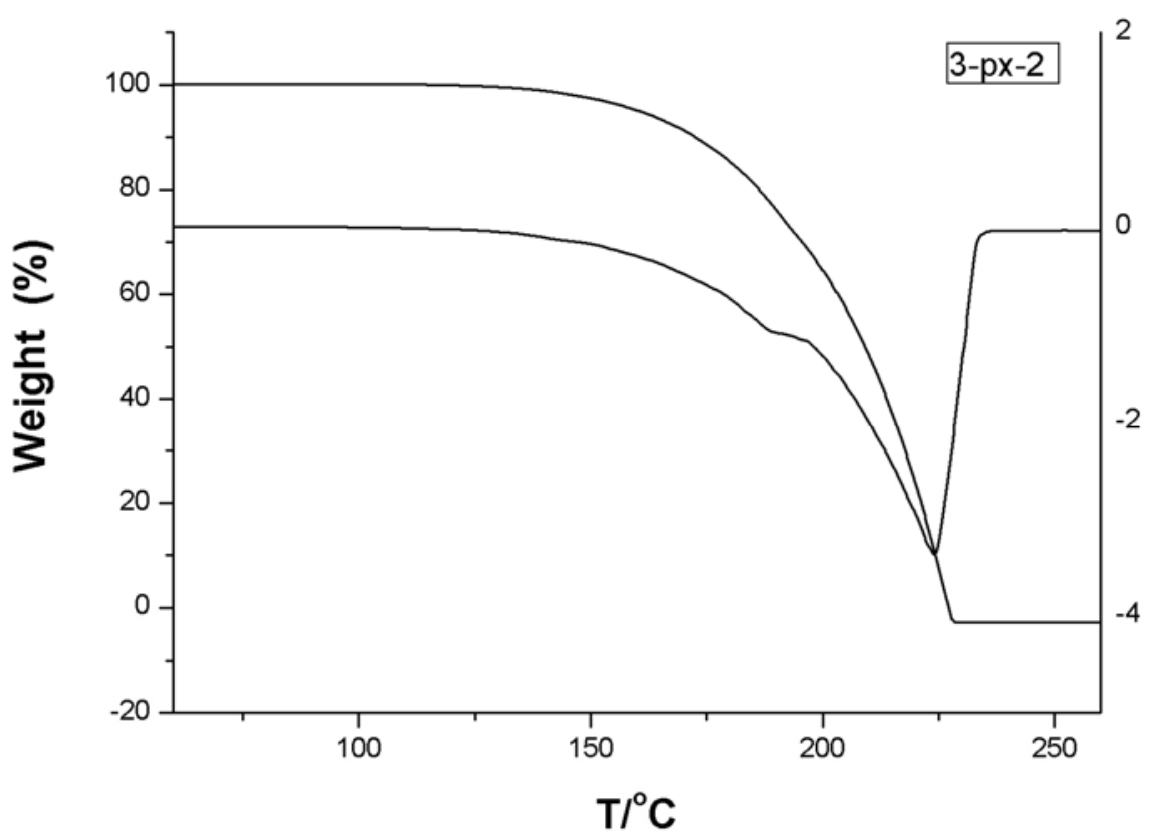


Figure 10 IR spectra of TPX and its decomposition residues, observed at room temperature (top) and $150^{\circ} \mathrm{C}$ (bottom.)

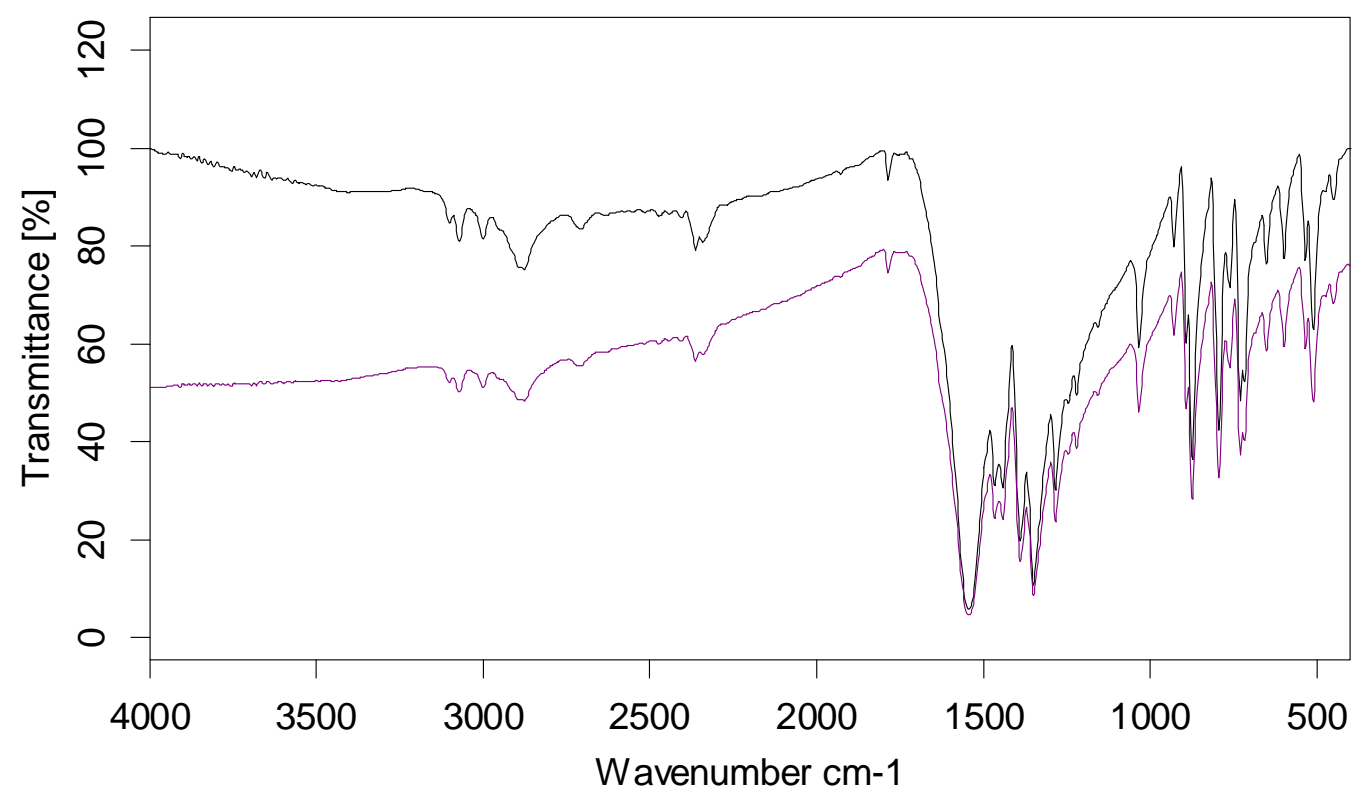

The second endothermic process is wider, with a peak temperature of $228.1{ }^{\circ} \mathrm{C}$. This shows the largest mass loss rate of $23.3 \% / \mathrm{min}$ at $185.0{ }^{\circ} \mathrm{C}$ and a mass loss is $53.2 \%$. From $190.0 \sim 202.0{ }^{\circ} \mathrm{C}$ the mass change is $22.7 \%$. After $202.0{ }^{\circ} \mathrm{C}$ there is a slow mass loss process. The compound decomposed completely at $350^{\circ} \mathrm{C}$. The DSC and TG-DTG curves of DPX and TPX are similar. They both have two endothermic peaks, the first intense and the second wider. In the TG-DTG curve they have same shape and differ only in the peak temperatures. This is in agreement with the fact that 2,3-DPX and 2,6-DPX are isomers and TPX only has one nitro-group more than DPX, so they should have similar thermal properties. Because TPX has the most nitro-groups it has the highest melting point and 2,6-DPX is more symmetrical than 2,3-DPX so it has the higher melting point.

\section{Conclusions}

In this paper we studied the synthesis of the various nitro-p-xylenes and selected the optimal conditions for this reaction. We grew single crystals from an appropriate solution and studied the crystal structures of 2,3-DPX and TPX. The thermal properties of dinitro- $p$-xylene and trinitro- $p$-xylene are similar. Because the content of nitrogen of trinitro- $p$-xylene is higher it has potential application as a precursor for energetic materials.

\section{Experimental}

\section{General}

A Perkin- Elmer Pyris-1 DSC was used for DSC measurements. Dry, oxygen-free nitrogen was used to purge the DSC at $20 \mathrm{~mL} / \mathrm{min}$. The heating rate was $10{ }^{\circ} \mathrm{C} / \mathrm{min}$ and the sample mass was about 
$0.5 \mathrm{mg}$ contained in sealed aluminum pans. A Perkin-Elmer Pyris-1 TG analyzer was used for thermogravimetric analysis. About $0.5 \mathrm{mg}$ of sample was held in a platinum pan, in a flow of dry, oxygen-free nitrogen at $20 \mathrm{~mL} / \mathrm{min}$, and the heating rate was $10^{\circ} \mathrm{C} / \mathrm{min}$. A Bruker Equinox $55 \mathrm{FT}-\mathrm{IR}$ spectrometer (KBr pellet) was used in the range of $400-4000 \mathrm{~cm}^{-1}$. The $p$-xylene used was A.R. grade. All nitrations were carried out with mixed acid prepared from sulfuric acid (specific gravity, $1.84 \mathrm{~g} / \mathrm{cm}^{3}$ ) and nitric acid (specific gravity, $1.50 \mathrm{~g} / \mathrm{cm}^{3}$ ).

\section{Synthesis of mononitro-p-xylene (MNP)}

The nitration was carried out in a flask with 4 necks. For the mononitration, the $p$-xylene was adding into the mixed acid. The reaction temperature and the amount of $p$-xylene added were recorded to ensure good temperature control and an even rate of addition of the $\mathrm{p}$-xylene. A reaction temperature below $13.28^{\circ} \mathrm{C}$ cannot be used because $p$-xylene solidifies. A small amount of oxidation product was observed during every nitration and it became more and more prevalent with higher temperatures, longer reaction times and lower D.V.S. values. The presence and extent of the oxidation was indicated by the amount of brown fumes of nitrogen dioxide liberated during the reaction. After the addition of all of the $p$-xylene, stirring was continued for 10 minutes, then the reaction mixture was slowly and carefully added to a beaker containing chipped ice (300-400 g). Separation of the two layers occurred after 30 minutes. The nitro-p-xylene layer was washed twice with portions of water $(100 \mathrm{~mL})$, $10 \%$ sodium carbonate solution, and finally with water again. Later the nitro-p-xylene was dried with anhydrous calcium sulfate. The only boiling point for nitro-p-xylene recorded in the literature is $238.5^{\circ}$ to $239^{\circ} \mathrm{C}$ at $739 \mathrm{~mm} \mathrm{Hg}$. The boiling point of the compound made in this work is $241 \sim 242^{\circ} \mathrm{C}$ at atmospheric pressure.

\section{Synthesis of dinitro-p-xylene (DPX)}

In order to produce the dinitro-p-xylene, we adopted the procedure for nitration of mononitro- $p$-xylene, as the reaction is similar to the mononitration of $p$-xylene. Mononitro-p-xylene can be used for next nitration without purification. The nitro- $p$-xylene was decanted from the mixed acid then it was added to the flask and heated to a temperature $5 \sim 10^{\circ} \mathrm{C}$ below the desired temperature for the experiment. The agitator was started and the mixed acid added dropwise at such a rate the temperature quickly raised to the desired value where it was controlled for $0.5 \mathrm{~h}$. Then the reaction mixture was poured onto crushed ice, the precipitate filtered off, washed with aqueous sodium bicarbonate and then water. The product was recrystallized from the minimum amount of glacial acetic acid, filtered, washed with methanol and dried under vacuum at $60^{\circ} \mathrm{C}$ to give DPX. All three dinitro- $p$-xylenes were formed on direct nitration according to Lellmann [7], who obtained only 2 grams of 2,5-compound from 100 grams of solid product. All other investigators report only the 2,3and 2,6-dinitro-p-xylenes. In this work we attempted to separate the isomers using successive recrystallizations. The solid product from the nitration is dissolved in ethyl alcohol and the solution evaporated slowly until long pale yellow crystals appeared. These were filtered from the solution, which was returned to the beaker for further evaporation. In this solution the crystals of 2,3-dinitro-p-xylene was obtained. The 2,6- isomer was separated in pure form relatively easily because of its low solubility in cold ethyl alcohol, in which the 2,3-isomer is soluble. In this process 
we obtained crystals of 2,3-dinitro-p-xylene. MS (m/e): $196\left(\mathrm{M}^{+}, 100\right)$. Analysis for DPX: Calcd.: C 49.24, H 4.19, N 14.17; Found: C 48.98, H 4.08, N 14.28; The FT-IR traces of the 2,6-dinitro-p-xylene and 2,3-dinitro-p-xylene are shown in Figure 11 and Figure 12, respectively.

From Figures 11 and 12 we can observe the mainly absorptions of some function groups are as follows: $\delta_{\mathrm{C}-\mathrm{NO} 2} 559 \mathrm{~cm}^{-1}, v_{\mathrm{O}-\mathrm{N}} 710 \mathrm{~cm}^{-1}, v_{\mathrm{C}-\mathrm{H}} 883 \mathrm{~cm}^{-1}, v_{\mathrm{NO} 2}^{\mathrm{s}} 1389 \mathrm{~cm}^{-1}, 1285 \mathrm{~cm}^{-1}, v^{\text {as }}{ }_{\mathrm{NO} 2} 1533 \mathrm{~cm}^{-1}$, $v_{\mathrm{C}-\mathrm{H}} 3088 \mathrm{~cm}^{-1}$.

Figure 11. The FT-IR figure of 2,6-dinitro-p-xylene

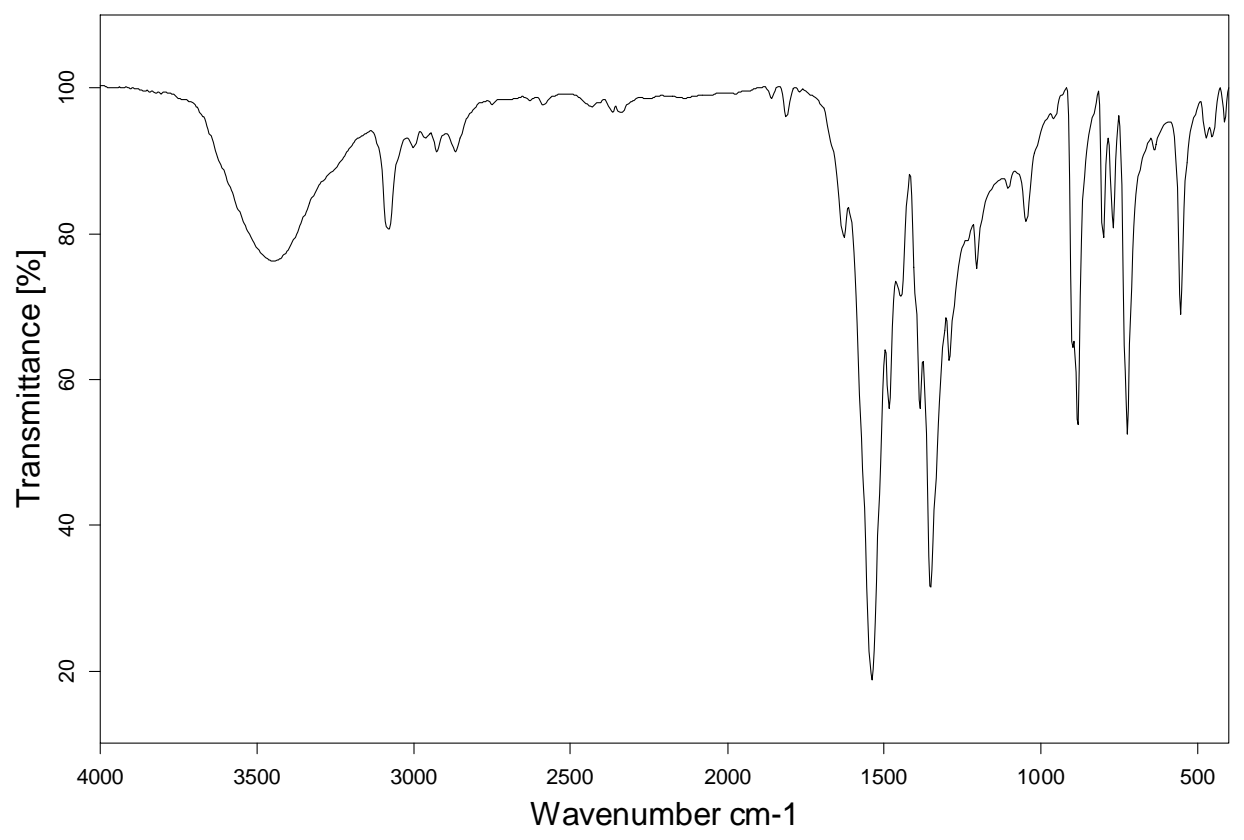

Figure 12. The FT-IR figure of 2,3-dinitro-p-xylene

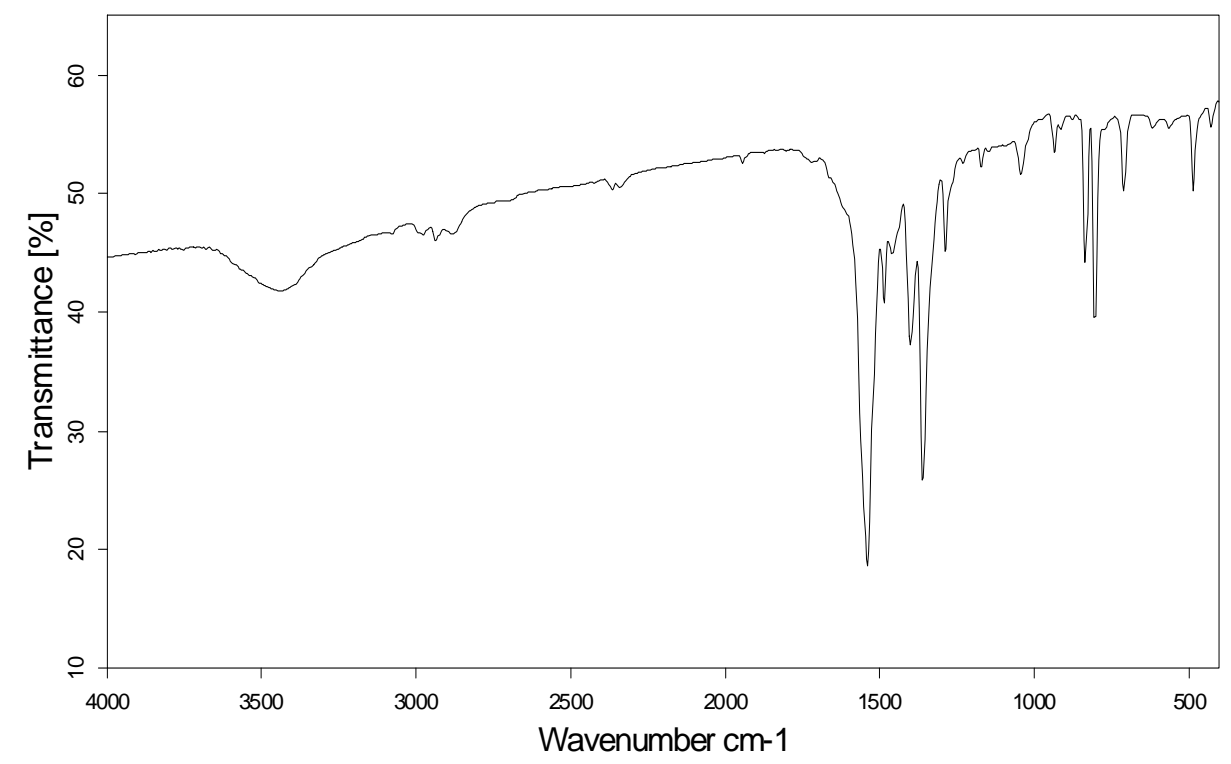


Synthesis of trinitro-p-xylene (TPX)

p-Xylene (10 g) was added dropwise over a certain period to a stirred mixture of nitric acid $(7 \mathrm{~mL})$, sulphuric acid $(25 \mathrm{~mL})$ and water $(15 \mathrm{~mL})$ so as not to allow the temperature to exceed $50^{\circ} \mathrm{C}$. After the addition, the mixture was poured into a separating funnel so that the bottom layer of residual acid could be removed. The product-containing top layer was added to sulphuric acid $(28 \mathrm{~mL})$ and the whole added to a mixture of nitric acid $(6.5 \mathrm{~mL})$, sulphuric acid $(1 \mathrm{~mL})$ and water $(0.5 \mathrm{~mL})$ at $70^{\circ} \mathrm{C}$. When the addition was complete, the temperature was raised to $80{ }^{\circ} \mathrm{C}$ for $10 \mathrm{~min}$, then slowly increased to $100^{\circ} \mathrm{C}$, and finally increased rapidly to $120{ }^{\circ} \mathrm{C}$ where it was maintained for $1 \mathrm{~h}$. The reaction mixture was then poured onto crushed ice, the precipitate filtered off and washed with aqueous sodium bicarbonate and then water. The product was recrystallized from the minimum amount of glacial acetic acid, filtered, washed with methanol and dried under vacuum at $60{ }^{\circ} \mathrm{C}$ to yield TPX (8.5 g), m.p. $140.9^{\circ} \mathrm{C} . \mathrm{MS}$ (m/e): $241\left(\mathrm{M}^{+}, 100\right)$. Analysis for TPX: Calcd. C 40.35, H 3.05, N 17.17; Found: C $39.83 \mathrm{H} 2.91 \mathrm{~N} 17.43$; IR $\left(\mathrm{cm}^{-1}\right)$ : $-\mathrm{C}_{-}-\mathrm{NO}_{2}: v_{\mathrm{NO}_{2}}^{a s} 1544, v_{\mathrm{NO} 2}^{\mathrm{s}} 1350,-\mathrm{O}-\mathrm{NO}_{2}: v_{\mathrm{NO} 2}^{\mathrm{s}} 1284$, $v_{\mathrm{C}-\mathrm{H}} 3100,3076, \delta_{\mathrm{C}-\mathrm{H}} 875 ;{ }^{1} \mathrm{H}-\mathrm{NMR}$ (DMSO) $\delta \mathrm{ppm} 8.467\left(\mathrm{~s}, 1 \mathrm{H}, \mathrm{C}_{6} \mathrm{H}\right), 2.476\left(\mathrm{~s}, 3 \mathrm{H}, \mathrm{CH}_{3}\right), 2.393$ $\left(\mathrm{s}, 3 \mathrm{H}, \mathrm{CH}_{3}\right.$ ). The D.V.S. factor is defined by Groggins [16] as the actual sulfuric acid divided by the total water present when nitration is completed, both values being on a weight basis. Hence, water introduced with the reactants-mixed acid and hydrocarbon and water formed in the reaction are both accounted for in the D.V.S. Although it might be more scientific to use a mole ratio rather than a weight ratio to express water-sulfuric acid ratio, the fact that analyses of the reactants are given on a weight basis leads to the use of D.V.S. as a plant operating value. The relationship can be calculated from the equations:

$$
\text { D.V.S. }=\frac{\text { Wt. of } \mathrm{H}_{2} \mathrm{SO}_{4} \text { used }}{\text { Wt. of } \mathrm{H}_{2} \mathrm{O} \text { at end of reaction }}=\frac{\text { moles }_{\mathrm{H}_{2} \mathrm{SO}_{4}} \times 98}{\text { moles }_{\mathrm{H}_{2} \mathrm{O}} \times 18}=5.444 \frac{\text { moles }_{\mathrm{H}_{2} \mathrm{SO}_{4}}}{\operatorname{moles}_{\mathrm{H}_{2} \mathrm{O}}} \text { or } \frac{\mathrm{Moles}_{\mathrm{H}_{2} \mathrm{SO}_{4}}}{\mathrm{Moles}_{\mathrm{H}_{2} \mathrm{O}}}=0.1837 \text { D.V.S. }
$$

In this work we selected the optimal reaction conditions for the synthesis of nitro-p-xylene that are summarized in Table 1.

Table 1 The optimal reaction conditions for synthesis nitro-p-xylene

\begin{tabular}{lccc}
\hline p-Xylene & Mononitro- & Dinitro- & Trinitro- \\
\hline Highest reaction temperature, ${ }^{\circ} \mathrm{C}$ & 30 & 80 & 120 \\
Nitration time, min. & 30 & 30 & 60 \\
D.V.S. & 3.0 & 8.0 & 27.3 \\
$\mathrm{HNO}_{3}:$ p-xylene, mole ratio & 1.10 & 1.10 & 3.55 \\
\hline
\end{tabular}

\section{References}

1. Guisnet, M.; Gnep, N. S.; Morin, S. Micropor. Mesopor. Mat. 2000, 35-36, 47-59

2. Aboul-Gheit, A. K.; Abdel-Hamid, S. M.; Emam, E. A. Catalytic para-xylene maximization alkylation of toluene with methanol on platinum loaded zeolite catalysts prepared via different routes. Appl. Catal. A: Gen. 1999, 179, 107-115.

3. Glinzer, E.; Fitting, R. Ann. 1865, 136, 307-308.

4. Nolting, E.; Forel, S. Ber. 1885, 18, 2680. 
5. Konowalow, M.; Gurewitsch, Ch. J. Russ. Phys. Chem. Soc. 1905, 27,537-41; [Chem. Zentr., 1905, 76, II,818].

6. Batchelder, G. W.; Nagle, W.M.; Vyverberg, J.C.; Willis, J. M. U.S. Patent No. 2,400,904, 1946.

7. Lellmann, E. Ann. 1885, 228, 250-3.

8. Giua, M. Gazz. Chim. Ital. 1919, 49, 149.

9. Davis, T. L. "Chemistry of Powder and Explosives"; John Wiley. \& Sons: New York, 1941; pp. 133-5, 141-150

10. Groggins, P.H. "Unit Processes in Organic Synthesis”; McGraw-Hill Book Co.: New York, 1947; pp. $48-51$

11. Shipp, K.G.; Kaplan, L.A. Reaction of a substituted polynitrotoluene II. The generation and reactions of 2,4,6-trinitrobenzylanion, J. Org. Chem. 1966, 31, 857.

12. Atkin, R.L.; Hollins, R.A.; Wilson, W.S. Synthesis of polynitro compounds. Hexasubstituted benzenes, J. Org. Chem. 1986, 51, 3261-3266.

13. CCDC number 258942 contains the supplementary crystallographic data for this paper. These data can be obtained free of charge via www.ccdc.cam.ac.uk/conts/retrieving.html (or from the CCDC, 12 Union Road, Cambridge CB2 1EZ, UK; fax: +44 1223 336033; e-mail: deposit@.ccdc.cam.ac.uk).

14. Sheldrick, G. M. SHELXS98 Program for the Solution of Crystal Structure; University of Gottingen: Gottingen, Germany; 1998.

15. Liu, Y.; Zhang, T.; Zhang, J.; Guo, J.; Yu, K. Preparation, Structural Characterization and the Molecular Structure of 2,3,5-trinitro-p-xylene. Struct. Chem. in press.

16. Groggins, P. H. "Unit Processes in Organic Synthesis”; McGraw-Hill Book Co.: New York, 1947; p. 25.

Sample availability: Contact the author.

(C) 2005 by MDPI (http://www.mdpi.org). Reproduction is permitted for noncommercial purposes. 